Rev. Bras. Saúde Prod. Anim., Salvador, v.16, n.4, p.811-817 out../dez.., 2015 http://www.rbspa.ufba.br ISSN 15199940

http://dx.doi.org/10.1590/S1519-99402015000400005

\title{
Uso de aditivos nas fases pré-alojamento e pré-inicial sobre o peso corporal e do trato digestório de pintos de corte
}

\author{
Use of additives in pre-housing and pre-start phases of rising on corporal and \\ grastrintestinal tract weight of broiler chicks
}

\author{
REIS, Túlio Leite ${ }^{1 *}$; CALIXTO, Lígia Fátima Lima ${ }^{1}$; ALVES, Osvanira dos Santos ${ }^{1}$; \\ LEMOS, Marina Jorge de ${ }^{1}$; LIMA, Marcos Fabio de ${ }^{1}$; TORRES-CORDIDO, Karoll \\ Andrea Alfonso ${ }^{2}$; CURVELLO, Fernando Augusto ${ }^{1}$; SOUSA, Felipe Dilelis de \\ Resende $^{1}$
}

\author{
${ }^{1}$ Universidade Federal Rural do Rio de Janeiro, Departamento de Produção Animal, Seropédica, Rio de \\ Janeiro, Brasil. \\ ${ }^{2}$ Universidade Estadual do Norte Fluminense Darcy Ribeiro, Centro de Ciências e Tecnologias Agropecuárias, \\ Laboratório de Zootecnia e Nutrição Animal, Campos dos Goytacazes, Rio de Janeiro, Brasil. \\ *Endereço para correspondência: tulioreis@hotmail.com
}

RESUMO

Objetivou-se com este trabalho verificar o uso de ração nas fases de pré-alojamento e pré-inicial contendo prebiótico ou antibiótico como forma de se avaliar o impacto dessa nutrição sobre a perda de peso no trajeto incubatório-granja, assim como no peso dos órgãos do trato digestório de pintinhos de corte. Foram utilizados 720 pintos de corte, linhagem Cobb 500, distribuídos em quatro tratamentos em um delineamento inteiramente casualisado (ração sem aditivos nas fases de préalojamento e pré-inicial; ração com prebiótico nas fases pré-alojamento e pré-inicial; consumo de ração com antibiótico nas fases pré-alojamento e pré-inicial; Jejum no pré-alojamento e ração sem aditivo na fase pré-inicial). No incubatório, os pintos foram pesados e foi fornecida a ração préalojamento nas caixas de transporte. No galpão experimental, as aves foram pesadas novamente para calcular a perda de peso durante o trajeto incubatório-granja, e logo após as aves foram alojadas, dividindo as aves de cada tratamento em 6 repetições de 30 aves cada. A densidade de alojamento foi de 10 aves $/ \mathrm{m}^{2}$. Com um e sete dias de alojamento, uma ave por parcela foi abatida por deslocamento cervical para dissecção e pesagem dos órgãos gastrointestinais. A utilização de aditivos prebiótico ou antibiótico nas rações préalojamento e pré-inicial não contribuiu na diminuição da perda de peso durante o trajeto incubatório-granja, assim como seu uso não promoveu maior peso dos órgãos gastrointestinais.

Palavras-chave: Avilamicina, $\beta$-glucanos, mananoligossacarídeos, nutrição neonatal, trato gastrointestinal

\section{SUMMARY}

The objective of this work was to verify the use of prebiotic or antibiotic in pre-housing and pre-start diets as a way to assess the impact of that nutrition on the corporal weight loss during path from hatchery tofarm, as well as the weight of digestive organs of chicks. Seven hundred and twenty dayold broiler chicks, Cobb 500, were distributed in four treatments in a completely randomized design (diet without additives in the pre - housing and pre - start phases; diet with prebiotic in the prehousing and pre-start phases; diet with antibiotic in the pre-housing and pre - start phases; Fasting in the pre-housing and diet without additives in the pre-start phase). In the hatchery, the chicks were weighed and were provided to pre-housing diets in the transportation crates. In the experimental house, the birds were weighed again to calculate the weight loss during the course hatchery-farm, and soon after the birds were housed, dividing them into 6 replicates of 30 birds per treatment. The housing density was 10 birds $/ \mathrm{m}^{2}$ With 1 and 7 days-old -, a bird per plot was harvested by cervical dislocation for dissection and weighing gastrointestinal organs. The use of prebiotic or antibiotic in pre-housing and pre-starter diets does not contribute in reducing weight loss during the course harchery-farm, as well as their use does not promote greater weight of gastrointestinal organs.

Keywords: $\quad$ Avilamicin, $\quad \beta$-glucans, mananoligossacarídes, neonatal nutrition, gastrointestinal tract 


\section{INTRODUÇ̃̃̃O}

No ano de 2013, o Brasil produziu cerca de 6,147 bilhões de frangos de corte, tendo uma produção média por mês de cerca de 500 milhões de pintos de corte (AVISITE, 2014). Apesar desta grande produção, existem alguns fatores que acarretam perdas no rendimento da incubação implicando em nascimentos desuniformes e aumento na amplitude da janela de nascimento de até 36 horas desde os primeiros ovos eclodidos até a retirada de todos os pintinhos. Se somarmos a isso o tempo gasto nos processos de sexagem e vacinação, ocorridos no incubatório, e o tempo do transporte, os pintos de corte podem chegar com mais de 48 horas de nascidos à granja, quando só então terão acesso ao alimento (CAREGHI et al., 2005; DALMAGRO, 2012). Para melhorar o desempenho inicial dos pintos e, consequentemente, do lote final, muitos estudos têm sido realizados com o objetivo de avaliar as vantagens do fornecimento de uma ração durante $\mathrm{o}$ transporte entre $\mathrm{o}$ incubatório e a granja onde ocorrerá o alojamento, chamada ração préalojamento (CAREGHI et al., 2005; AGOSTINHO et al., 2012). O desenvolvimento morfológico do intestino delgado acelera em pintinhos arraçoados imediatamente após a eclosão (NOY \& SKLAN, 2000), enquanto que a demora no acesso à ração pode provocar efeito contrário (GEYRA et al., 2001). Nesta fase, a velocidade de aumento do peso do intestino é maior que a do peso corporal como um todo e este processo atinge um pico máximo por volta de seis a oito dias para os intestinos, entretanto, outros órgãos do sistema digestivo, como o pâncreas e a moela, não apresentam o mesmo ritmo de crescimento
(TAVERNARI \& MENDES, 2009). Outro evento muito importante que ocorre logo após a eclosão é a colonização do trato gastrointestinal por microorganismos benéficos, portanto, nesse momento, a inclusão de aditivos melhoradores de desempenho e equilibradores da microflora (antibióticos e prebióticos, respectivamente), que são incorporados à ração, podem auxiliar essa colonização da flora intestinal, permitindo dessa forma uma melhor absorção de nutrientes. Diante do exposto, o objetivo deste estudo foi avaliar o efeito da inclusão de aditivos (prebióticos e antibióticos) à ração nas fases préalojamento e pré-inicial sobre a perda de peso corporal durante $o$ trajeto incubatório-granja e o peso dos órgãos do trato gastrointestinal de pintinhos de corte.

\section{MATERIAL E MÉTODOS}

O experimento teve início em novembro de 2012, no incubatório Rio Minas da empresa Reginaves Indústria e Comércio de Aves Ltda, localizado na cidade de São José da Lapa, no estado de Minas Gerais. Os dados de desempenho foram avaliados no Cento de Pesquisas Avícolas (CPA) do Instituto Federal do Rio de Janeiro (IFRJ), localizado no município de Pinheiral, estado do Rio de Janeiro, no período de 9 de novembro à 21 de dezembro de 2012.

No incubatório, pintos de corte recémeclodidos, da linhagem comercial Cobb 500 , provenientes de matrizes de 31 semanas de idade, foram classificados, sexados e vacinados. Para o experimento, foram utilizados 720 pintos machos com peso médio de 40 gramas, que foram distribuídos em um delineamento inteiramente ao acaso com quatro 
tratamentos de 180 aves cada, divididos em: 1 consumo de ração pré-alojamento sem aditivo; 2 consumo de ração préalojamento com prebiótico; 3 consumo de ração pré-alojamento com antibiótico; e 4 Jejum no pré-alojamento. Os pintos foram acondicionados em caixas de transporte forradas com papel corrugado e marcadas de acordo com o tratamento. A ração foi previamente distribuída nas caixas na quantidade de $2 \mathrm{~g}$ por ave (tratamentos 1, 2 e 3). As dietas experimentais fornecidas nas caixas de transporte foram as mesmas fornecidas na fase pré-inicial (de 1 a 7 dias), e foram formuladas à base de milho e farelo de soja, atendendo às necessidades nutricionais estabelecidas por Rostagno et al. (2011). O tempo total compreendido entre o nascimento no incubatório, $\mathrm{o}$ transporte e o alojamento das aves no galpão experimental foi de 24 horas.

Tabela 1. Composição das rações experimentais fornecidas nas fases de pré-alojamento (na caixa de transporte do incubatório à granja) e pré-inicial (de 1 a 7 dias)

\begin{tabular}{|c|c|}
\hline Ingredientes & $\%$ \\
\hline Milho $(8.55 \%$ PB $)$ & 58,2909 \\
\hline Farelo de soja (45.96\% PB) & 32,2372 \\
\hline Farinha de carne e ossos $(44.10 \% \mathrm{~PB})$ & 7,3649 \\
\hline Óleo de soja & 0,5102 \\
\hline Sal & 0,3787 \\
\hline Cloreto de colina & 0,0500 \\
\hline Suplemento mineral ${ }^{1}$ & 0,0500 \\
\hline Suplemento vitamínico ${ }^{2}$ & 0,0500 \\
\hline DL-Metionina & 0,3586 \\
\hline L-Lisina HCL & 0,3454 \\
\hline L-Treonina & 0,1641 \\
\hline Coccidiostático $^{3}$ & 0,0500 \\
\hline Aditivo $^{4}$ & 0,1500 \\
\hline Total & 100,00 \\
\hline \multicolumn{2}{|c|}{ Composição nutricional calculada } \\
\hline Energia metabolizável (Mcal/Kg) & 2,960 \\
\hline Proteína bruta $(\mathrm{PB} \%)$ & 22,40 \\
\hline Cálcio (\%) & 0,920 \\
\hline Fósforo disponível (\%) & 0,470 \\
\hline Cloro (\%) & 0,200 \\
\hline Sódio (\%) & 0,220 \\
\hline Potássio $(\%)$ & 0,590 \\
\hline Ácido Linoléico (\%) & 1,090 \\
\hline \multicolumn{2}{|c|}{ 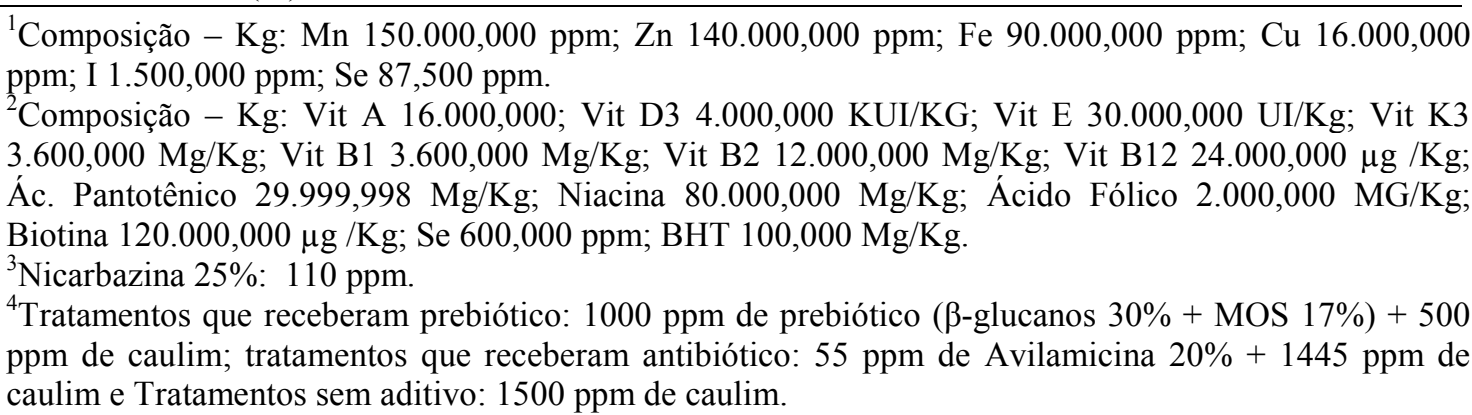 } \\
\hline
\end{tabular}


O prebiótico (Immunowall $\AA$ - ICC) utilizado continha na sua composição $\beta$ glucanos $(1-3, \quad 1-6) \quad 30 \% \quad \mathrm{e}$ mananoligossacarídeos (MOS) 17\%, derivados da levedura Saccharomyces cerevisiae. O antibiótico (Surmax ${ }^{\circledR} 200$ Elanco) utilizado foi Avilamicina 20\%. A quantidade do prebiótico e do antibiótico utilizada foi a mesma recomendada pelo fabricante conforme rótulo do produto. Foi adicionado em substituição ao equivalente em peso, o material inerte (caulim), permitindo a manutenção dos mesmos níveis nutricionais em todas as rações.

No galpão experimental, os pintos foram pesados individualmente e foram formadas seis parcelas de 30 aves por tratamento. As aves decada parcela foram alojadas em um de box de $3 \mathrm{~m}^{2}$ com comedouro tubular, bebedouros tipo nipple, aquecedores a gás e cama de maravalha de aproximadamente $10 \mathrm{~cm}$ de altura. O programa de luz utilizado foi de 24 horas de luz. Os pintos foram criados até os sete dias de idade.

Foram avaliadas as variáveis: perda de peso (g) durante o transporte do incubatório ao galpão e percentagem de perda de peso (\%) relativo ao peso corporal imediatamente após a eclosão; peso dos órgãos do trato gastrointestinal - após 24 horas e após sete dias do alojamento. Uma ave por parcela foi sacrificada em cada uma das datas por deslocamento cervical para aferição do peso $(\mathrm{g})$ do proventrículo + moela $\mathrm{e}$ intestinos + pâncreas. Os dados foram submetidos à análise de variância e às médias comparadas pelo teste de Tukey com 5\% de significância.

\section{RESULTADOS E DISCUSSÃO}

Durante o trajeto incubatório - granja não houve diferença significativa $(\mathrm{p}<0,05)$ de perda de peso entre pintinhos que se alimentaram da ração pré-alojamento e os que permaneceram em jejum, independente do aditivo fornecido nessa ração (Tabela 2). Esses resultados corroboram com Pedroso et al. (2005) que, pesquisando o uso de suplementos comerciais fornecidos durante intervalos de tempo de 24 horas ou 48 horas entre o nascimento e o alojamento, não verificaram diferença significativa entre aves que receberam ou não o suplemento. Entretanto, Almeida et al. (2006), pesquisando o fornecimento de ração logo após o nascimento, observaram maiores perdas de peso em aves que não receberam suplementação em períodos de 24 horas ou 48 horas de intervalo de alojamento em comparação com aves alojadas imediatamente. Esses autores observaram que a perda de peso foi maior à medida que aumentou $o$ intervalo entre a eclosão e o alojamento (ALMEIDA, 2006; PEDROSO et al., 2006). No presente estudo, esse tempo foi de aproximadamente 24 horas e o uso da ração pré-alojamento com prebiótico, antibiótico ou sem aditivo não promoveu menor redução da perda de peso dos pintos durante o transporte. O tempo de jejum no trajeto do incubatório à granja parece ter sido incapaz de promover uma perda de peso grande o suficiente, gerando um pior desempenho das aves em jejum, em comparação com as aves que receberam ração durante esse período.

A utilização da ração pré-alojamento com a inclusão dos aditivos não influenciou $(\mathrm{p}<0,05)$ o peso dos órgãos digestivos avaliados em pintos de corte com um e sete dias de idade (Tabela 3). Esses resultados contradizem os encontrados por Pedroso et al. (2006), que trabalhando com pintos de corte observou que pintos alimentados logo após a eclosão obtiveram maior peso absoluto de proventrículo + moela e intestino delgado comparado com aves 
Rev. Bras. Saúde Prod. Anim., Salvador, v.16, n.4, p.811-817 out../dez.., 2015 http://www.rbspa.ufba.br

que permaneceram durante 24 horas em jejum alimentar.

O mesmo foi observado por Cançado \& Baião (2002), que verificaram maior crescimento de intestinos de frangos de corte na fase inicial alimentados logo após a eclosão, em comparação com aves que sofreram jejum de 24 horas e 48 horas. A utilização da ração préalojamento com a inclusão dos aditivos não influenciou $(\mathrm{p}<0,05)$ o peso dos órgãos digestivos avaliados em pintos de corte com um e sete dias de idade (Tabela 3). Noy \& Sklan (2000) verificaram que pintinhos em jejum por 48 horas após a eclosão sofrem diminuição no peso, mas ainda assim durante estas 48 horas o peso do intestino delgado aumenta $60 \%$ em pintinhos desprovidos de alimento e $200 \%$ em pintinhos providos de alimentos, diferença esta de crescimento intestinal não observada neste estudo.

Tabela 2. Perda de peso corporal de pintos de corte durante o transporte do incubatório à granja

\begin{tabular}{lcc}
\hline \multirow{2}{*}{ Ração pré-alojamento } & \multicolumn{2}{c}{ Unidade } \\
\cline { 2 - 3 } & Gramas $^{1}$ & $\%^{2}$ \\
\hline Sem aditivo & 1,88 & 4,76 \\
Com prebiótico & 2,22 & 5,46 \\
Com antibiótico & 1,91 & 4,69 \\
Jejum & 1,98 & 4,90 \\
\hline Probabilidade & 0,6394 & 0,5592 \\
CV $(\%)$ & 23,13 & 23,19 \\
\hline
\end{tabular}

${ }^{1}$ Perda de peso em gramas; ${ }^{2}$ Perda de Peso em relação ao peso corpóreo.

Tabela 3. Peso médio de órgãos de pintos de corte que permaneceram em jejum na fase pré-alojamento e receberam ração no galpão contendo aditivos

\begin{tabular}{lcccc}
\hline \multicolumn{3}{c}{ Peso médio dos órgãos $(\mathrm{g})$} \\
\hline \multirow{2}{*}{ Tratamentos $^{1}$} & \multicolumn{1}{c}{ Proventículo + Moela } & \multicolumn{2}{c}{ Intestinos + pâncreas } \\
\cline { 2 - 5 } & 1 dia & 7 dias & 1 dia & 7 dias \\
\hline 1 & 5,91 & 13,79 & 4,80 & 21,95 \\
2 & 5,25 & 14,20 & 4,32 & 22,00 \\
3 & 5,69 & 14,99 & 5,18 & 22,95 \\
4 & 5,39 & 14,62 & 4,59 & 22,47 \\
\hline Probabilidade & 0,1127 & 0,1603 & 0,2742 & 0,9210 \\
\hline CV $(\%)$ & 13,55 & 16,42 & 16,42 & 13,67 \\
\hline
\end{tabular}

${ }^{1}$ Tratamentos: 1 Consumo de ração sem aditivo nas fases de pré-alojamento e pré-inicial; 2 Consumo de ração com prebiótico nas fases pré-alojamento e pré-inicial; 3 Consumo de ração com antibiótico nas fases pré-alojamento e pré-inicial; 4 Jejum no pré-alojamento e ração sem aditivo na fase pré-inicial.

Agostinho et al. (2012) também não observaram influência do fornecimento de ração pré-alojamento no peso de órgãos digestivos de frangos de corte na fase inicial. Durante esta fase pós-eclosão, a gema é utilizada preferencialmente para o desenvolvimento do intestino delgado (TAVERNARI \& MENDES, 2009), característica que ocorre na presença ou não de alimento, sendo que a presença de alimento acelera este processo (NOY \& SKLAN, 1998). Portanto, aves 
submetidas a jejum consomem uma maior quantidade da gema do saco vitelino para aumentar o crescimento intestinal, podendo apresentar desenvolvimento dos órgãos semelhante ao de aves que consumiram ração.

Este estudo permitiu concluir que a utilização de aditivos prebiótico ou antibiótico nas rações pré-alojamento e pré-inicial não reduz a perda de peso corporal durante o trajeto do incubatório até a granja, nem promovem maior peso dos órgãos do trato gastrointestinal em pintos de corte, não sendo indicada a utilização da ração pré-alojamento no tempo de jejum estudado (24 horas), o que poderia em granjas que adotem essas práticas, ser uma fonte de economia.

\section{REFERÊNCIAS}

AGOSTINHO, T.S.P.; CALIXTO, L.F.L.; GOMES, A.V.D.C.; TOGASHI, C.K.; CURVELLO, F.; DE LIMA, M.F. Desenvolvimento de órgãos do trato gastrintestinal e desempenho de frangos de corte arraçoados na fase préalojamento. Revista Brasileira de Saúde e Produção Animal [online], v.13, n.4, p.1143-1155, 2012.

ALMEIDA, J.; DAHLKE, F.; MAIORKA, A.; MACARI, M.; FURLAN, R. Efeito do jejum no intervalo entre o nascimento e o alojamento sobre o desempenho de frangos de corte provenientes de matrizes de diferentes idades. Archives of Veterinary Science, v.11, n.2, 2006.

AVISITE. Produção de pintos de corte aumentou $2,33 \%$ em 2013. Avisite, 2014. Disponível em: $<$ http://www.avisite.com.br/economia/i ndex.php?acao=producaopintos $>$. Acesso em: 11 abril. 2014.
CANÇADO, S.V.; BAIÃO, N.C. Efeito do período de jejum entre o nascimento e alojamento e da adição de óleo à ração sobre o desenvolvimento do trato gastrointestinal e atividade de lipase. Arquivos Brasileiros de Medicina Veterinária e Zootecnia, v.54, n.6, p.623-629, 2002.

CAREGHI, C; TONA, K.; ONAGBESAN, O.; BUYSE, J.; DECUYPERE, E.; BRUGGEMAN, V. The effects of the spread of hatch and interaction with delayed feed access after hatch on broiler performance until seven days of age. Poultry Science, v.84, n.8, p.1314-1320, 2005.

DALMAGRO, M. Influência da nutrição neonatal no desempenho produtivo e sanitário de frangos de corte. Vetanco, 2012. Disponível em: $<$ http://www.vetanco.com.br/wpcontent/uploads/2012/11/Influencia-danutricao-neonatal-no-desempenhoprodutivo-e-sanitario-de-frangos-decorte-DVM-MSc-MarceloDalmagro.pdf $>$. Acesso em: 05 de jan. 2012.

GEYRA, A.; UNI, Z.; SKLAN, D. The effect of fasting at different ages on growth and tissue dynamics in the small intestine of the young chick. British Poultry Science, v.86, p.53-61, 2001.

NOY, Y.; SKLAN, D. Metabolic responses to early nutrition. Journal Applied Poultry Research, v.7, p.437451, 1998.

NOY, Y.; SKLAN, D. Hydrolysis and Absorption in the Small Intestines of Post hatch Chicks. Poultry Science, v.79, p.1306-1310, 2000. 
PEDROSO, A.A.; STRINGHINI, J.H.;

MOGYCA, L.N.S.; BARCELLOS, C.M.; BARBOSA, C.E, GONTIJO, DE

L.F. Suplementos utilizados com o hidratantes nas fases pré-alojamento e pós-alojamento para pintos recém eclodidos. Pesquisa Agropecuária Brasileira, v.40, p.627-632, 2005.

PEDROSO, A.A.; CHAVES, L.S.; LOPES, K.L.A.M.; CAFÉ, M.B.; LEANDRO, N.S.M.; STRINGHINI, J.H. Inoculação de nutrientes em ovos de matrizes pesadas. Revista Brasileira de Zootecnia, v.35, n.5, p.218-226, 2006.

ROSTAGNO, H.S.; ALBINO, L.F.T.; DONZELE, J.L.; GOMES, P.C.; OLIVEIRA, R.F.; LOPES, D.C.; FERREIRA, A.S.; BARRETO, S.L.T.; EUCLIDES, R.F. Tabelas brasileiras para aves e suínos: Composição de alimentos e exigências nutricionais. Viçosa, MG: Universidade Federal de Viçosa, 2011.252p.

TAVERNARI, F.C.; MENDES, A.M.P. Desenvolvimento, crescimento e características do sistema digestório de aves. Revista Eletrônica Nutritime, v.6, n.6, p.1103-1115, 2009.

Data de recebimento: $23 / 05 / 2014$

Data de aprovação: 06/10/2015 